\title{
Determinants of Perceived Stress in Individuals with Obesity: Exploring the Relationship of Potentially Obesity-Related Factors and Perceived Stress
}

\author{
Florian Junne $^{a} \quad$ Katrin Ziser $^{a} \quad$ Katrin Elisabeth Giel $^{a} \quad$ Kathrin Schag $^{a}$ \\ Eva Skoda $^{a} \quad$ Isabelle Mack $^{a} \quad$ Andreas Niess $^{b} \quad$ Stephan Zipfel ${ }^{a}$ \\ Martin Teufelc \\ a Department of Psychosomatic Medicine and Psychotherapy, Medical University Hospital \\ Tübingen, Tübingen, Germany; ${ }^{b}$ Department of Sports Medicine, Medical University \\ Hospital Tübingen, Tübingen, Germany; ${ }^{C}$ Department of Psychosomatic Medicine and \\ Psychotherapy, LVR-University Hospital, University Duisburg-Essen, Essen, Germany
}

\section{Key Words}

Obesity · Stress · Eating

\begin{abstract}
Objective: Associations of specific types of stress with increased food intake and subsequent weight gain have been demonstrated in animal models as well as in experimental and epidemiological studies on humans. This study explores the research question of to what extent potentially obesity-related factors determine perceived stress in individuals with obesity. Methods: $\mathrm{N}=547$ individuals with obesity participated in a cross-sectional study assessing perceived stress as the outcome variable and potential determinants of stress related to obesity. Based on the available evidence, a five factorial model of 'obesity-related obesogenic stressors' was hypothesized, including the dimensions, 'drive for thinness', 'impulse regulation', 'ineffectiveness', 'social insecurity', and 'body dissatisfaction'. The model was tested using multiple linear regression analyses. Results: The five factorial model of 'potentially obesity-related stressors' resulted in a total variance explanation of adjusted $R^{2}=0.616$ for males and adjusted $R^{2}=0.595$ for females for perceived stress. The relative variance contribution of the five included factors differed substantially for the two sexes. Conclusion: The findings of this cross-sectional study support the hypothesized, potentially obesity-related factors: 'drive for thinness', 'impulse regulation', 'ineffectiveness', 'social insecurity', and 'body dissatisfaction' as relevant determinants of perceived stress in individuals with obesity.
\end{abstract}


Junne et al.: Determinants of Perceived Stress in Individuals with Obesity: Exploring the Relationship of Potentially Obesity-Related Factors and Perceived Stress

\section{Introduction}

Associations of specific types of stress with increased food intake and subsequent weight gain have been demonstrated in animal models as well as in experimental and epidemiological studies on humans [1-11]. Stress in general can be defined as a 'real or perceived threat to homeostasis' $[12,13]$. The physiological stress response inter alia is mediated by components of the hypothalamic-pituitary-adrenal (HPA) axis, including consequences on the regulation of appetite, food selection, and energy metabolism [14-18]. Increased cortisol levels may thereby lead to altered food selection towards more calorie-dense foods and increased food intake $[7,19]$. Given these findings, the role of perceived stress may be of importance in the onset and course of obesity.

In regard to the differential roles of different types of stress, it has been shown that in acute stress situations with a predominant activation of the sympathetic-adrenal-medullary system, appetite and hence calorie intake may be reduced. Inversely, during exposure to chronic stress, with a predominant activation of the pituitary-adrenal-cortical system, increased intake of palatable and calorie-dense foods may ultimately cause weight gain [8]. The latter is the case especially for individuals with high cortisol reactivity profiles in response to stress [20-22]. In a naturalistic study by Foss and colleagues [23], individuals with high cortisol reactivity showed for example higher snack intake rates in response to daily hassles than the control group [22-26].

Besides showing that chronic stress is an important driver of increased food intake and weight gain in general, evidence indicates that stressors that are perceived to be uncontrollable (ego-)threats to the individual lead to increased food intake more than stressors that are perceived as controllable challenges [6,30,31]. Furthermore, evidence from rat models suggests differences in subsequent eating behavior when comparing physical stress to emotional distress. Rodents that are exposed to emotional distress showed increased preferences towards saccharin drinks compared to water, whereas rodents that are physically stressed showed the inverse behavior [32-34]. In regard to social stressors, studies (including animal models) show associations of negative social stress with (visceral) fat accumulation and weight gain $[12,35,36]$.

Given the evidence on the relationship between specific psychological (chronic) stressors and weight gain, one might postulate that the stressor types identified in the literature presented above, i.e., chronic, uncontrollable, emotional and social distress, may act as barriers to weight management and may even contribute to further weight gain in individuals with obesity. If such chronic, subjectively uncontrollable, social or emotional stress is at the same time potentially associated with the characteristics or consequences of obesity itself, then this may lead to an adverse interplay of obesity, stress and eating.

Based on the above considerations, this study first seeks to answer the research question of whether the hypothesized potentially obesity-related factors determine perceived stress in individuals with obesity. Secondly, if a determination is found, then to what extent do the hypothesized stressors contribute to the variance of perceived stress in individuals with obesity? It was hypothesized that the following potentially obesity-related dimensions determine perceived stress in individuals with obesity in the forms of: 'body dissatisfaction', 'drive for thinness', 'impulse regulation', 'ineffectiveness', and 'social insecurity'. Higher scores on one of the latter dimensions are thereby hypothesized to be associated with a higher level of perceived stress. 


\section{Material and Methods}

\section{Recruitment and Data Management:}

Individuals of both sexes with BMI $\geq 30 \mathrm{~kg} / \mathrm{m}^{2}$ presenting at a tertiary university medical center for comprehensive, structured multi-professional assessment in regard to the physical and mental dimensions of obesity were included consecutively. Following informed consent, participants were given paper-based questionnaires, including a comprehensive set of standard instruments related to the study questions, and were subsequently weighed. Most study participants were referred to the program from their general practitioner for structured assessment and subsequent treatment recommendations. Potential referrals within the program range from conservative treatment including, e.g. obesity-specific cognitive-behavioral (group) therapy, to surgical bariatric interventions. Data were electronically transferred to SPSS software format and prepared for statistical analyses.

A total of 663 participants consented to participate in the study. Non-responder analyses were not performed. Data sets with missing values for one of the investigated variables were omitted before calculating multiple linear regression analyses, resulting in a sample size of 547 participants.

\section{Design and Instruments}

The study was conducted in a cross-sectional design using validated standard questionnaires to assess perceived stress, obesity, and eating behavior-related dimensions as well as symptoms of stress-related mental disorders (i.e., depression and anxiety). The Perceived Stress Questionnaire (PSQ-20) served as the standard instrument to assess the magnitude of stress as the main dependent variable. The PSQ-20 consists of 20 single items clustered in 4 subscales representing the stress-determining constructs 'worries', 'tension', 'joy', and 'demands'. The PSQ-20 was validated within diverse groups of healthy and diseased populations, showing good and satisfactory test properties [37,38]. Reliability in the present sample proved to be good to excellent for all four PSQ-20 subscales with Cronbach's $\alpha=0.784-0.851$. PSQ-20 sum scores are expressed as values between 0 and 1 .

The Eating Disorder Inventory 2 (EDI-2) was used to assess self-perceptions, emotions and cognitions of subjects in relation to 11 constructs relevant in the context of eating and weight pathology [39]. The EDI-2 has been developed for the multidimensional assessment of eating behavior and related constructs. The questionnaire comprises a total of 91 single items. Whilst the EDI was primarily used to assess underweightspectrum disorders, it has been increasingly applied to the context of normal-weight or overweight populations [40]. The EDI-2 has been validated in different populations with good test properties and can be seen as a gold standard instrument to assess eating- and weight-related cognitive and emotional dimensions [39, 41]. The reliability proved to be good to excellent for most of the EDI-2 subscales with Cronbach's $\alpha=0.704-$ 0.879 . Only the subscales 'maturity fears' $(\alpha=0.564)$ and 'asceticism' $(\alpha=0.620)$ showed a poorer reliability. Sum scores of the four constructs (subscales) from the EDI-2 were selected on the basis of theoretically derived criteria to enter the regression model (see details for model development below).

Subscales of the Patient Health Questionnaire (PHQ) for anxiety and depression were used to monitor the stress-related burden of mental health symptoms within the study population [42, 43]. The reliability of the PHQ subscales proved to be good to excellent with Cronbach's $\alpha=0.729-0.867$.

\section{Model Development}

To enter the theoretically derived model of 'potentially obesity-related stressors', factors needed to fulfil two criteria:

1) Show characteristics of at least one of the identified obesogenic types of stress, i.e., a) chronic, b) uncontrollable, c) emotionally, or d) socially distressing.

2) Be potentially linked with obesity itself or its consequences. On the basis of these criteria, it was hypothesized that the following constructs determine stress in obese individuals: a) 'Body Dissatisfaction', b) 'Drive for Thinness', c) 'Impulse Regulation', d) 'Ineffectiveness', e) 'Social Insecurity'. Each dimension is represented by the respective subscale of the EDI-2 [39].

\section{Model Dimensions}

- $\quad$ Construct a) 'Body Dissatisfaction' describes the degree of dissatisfaction with one's general body and the size of body parts and was selected for representing an emotionally distressing factor that is potentially linked to obesity [39]. 
Table 1. Demographic characteristics

\begin{tabular}{|c|c|c|c|c|}
\hline Demographic characteristics & $\operatorname{Men}(n=156)$ & Women $(n=391)$ & $\mathrm{p}^{\mathrm{c}}$ & Total $(\mathrm{N}=547)$ \\
\hline Age, years ${ }^{a}$ & $43.2(12.8)$ & $40.6(11.8)$ & 0.039 & $41.4(12.2)$ \\
\hline Marital status ${ }^{b}$ & & & 0.001 & \\
\hline Single & $66(42)$ & $124(32)$ & & $190(35)$ \\
\hline Married & $75(48)$ & $183(47)$ & & $258(47)$ \\
\hline Separated or divorced & $15(10)$ & $57(15)$ & & $72(13)$ \\
\hline Widowed & $0(0)$ & $14(4)$ & & $14(3)$ \\
\hline Others & $0(0)$ & $11(3)$ & & $11(2)$ \\
\hline Education $^{b}$ & & & 0.087 & \\
\hline$<$ High school & 107 (70) & $278(72)$ & & 385 (71) \\
\hline High school & $15(10)$ & $42(11)$ & & $57(11)$ \\
\hline >High school & $26(17)$ & $38(10)$ & & $64(12)$ \\
\hline Others & $6(4)$ & $27(7)$ & & $33(6)$ \\
\hline Employment ${ }^{b}$ & & & $<0.001$ & \\
\hline Student & $8(5)$ & $19(5)$ & & $27(5)$ \\
\hline Employed for wages & $76(49)$ & $178(46)$ & & $254(47)$ \\
\hline Self-employed & $10(6)$ & $19(5)$ & & $29(5)$ \\
\hline Unemployed & $26(17)$ & $44(11)$ & & $70(13)$ \\
\hline Retired & $26(17)$ & $42(11)$ & & $68(13)$ \\
\hline Others & $9(6)$ & $84(22)$ & & $93(17)$ \\
\hline
\end{tabular}

aData are mean-values (SD).

${ }^{b}$ Data represent frequency values (\%).

${ }^{c} \mathrm{p}$-values refer to the significance of Mann-Whitney-U (continuous data) or Pearson's Chi-Squared Tests (categorical data).

- $\quad$ Construct b) 'Drive for Thinness' in the EDI-2 describes a severe preoccupation with dieting and mental fixation on weight issues. This subscale was selected as being potentially chronic in nature for individuals with obesity, constituting an uncontrollable type of stress for individuals that, e.g., perceive the frustration of repeatedly driving for thinness without achieving (significant) weight loss [39].

- $\quad$ Construct c) 'Impulse Regulation' describes the tendency for impulsive actions, mood changes, alcohol abuse, and ruthlessness. Therefore, it was deemed an 'uncontrollable' stressor in nature that may at the same time reflect on the obesity-specific dimension of lack of impulse regulation concerning, e.g., (problematic) eating behavior [39].

- $\quad$ Construct d) 'Ineffectiveness' describes the feeling of being generally inadequate, insecure, worthless and hollow, and of having deficient control over one's life. This subscale was selected as representing an ego-threat type stressor that may be perceived by individuals with obesity, e.g. in regard to changes in (eating) behavior or lifestyle changes, i.e., being unable to establish new (eating) behaviors or daily (physical activity) routines to reduce weight, despite the explicitly and strongly perceived wish or plan to do so [39].

- Construct e) 'Social insecurity' describes the belief that social relationships are tense, insecure, disappointing, not worthwhile, and generally of low quality. This subscale was included based on the consideration that individuals with obesity may feel insecure in social contexts because of, e.g., assumed or experienced stigma or discrimination. Hence, this construct may represent the negative social type of stress [39].

All of the five constructs are assumed to be potentially chronic/recurrent, and all five constructs are assumed to potentially evoke negative emotions as a common cause of potentially obesogenic stress. 
Table 2. Clinical characteristics

\begin{tabular}{|c|c|c|c|c|}
\hline Clinical characteristics & $\operatorname{Men}(\mathrm{n}=156)$ & Women $(n=391)$ & $\mathrm{p}^{\mathrm{c}}$ & Total $(\mathrm{N}=547)$ \\
\hline BMI, $\mathrm{kg} / \mathrm{m}^{2 \mathrm{a}}$ & $45.8(8.6)$ & $45.3(8.0)$ & 0.731 & $45.35(8.2)$ \\
\hline \multicolumn{5}{|l|}{ PHQ anxiety \& depression } \\
\hline Panic syndrome ${ }^{\mathrm{b}}$ & $8(5)$ & $29(7)$ & 0.336 & $37(7)$ \\
\hline Other anxiety syndromes ${ }^{\mathrm{b}}$ & $6(4)$ & $44(11)$ & 0.007 & $50(9)$ \\
\hline Depression (PHQ-9 sum-score) ${ }^{a}$ & $9.2(5.8)$ & $9.97(6.0)$ & 0.152 & $9.75(6.0)$ \\
\hline Depression PHQ-9 sum-score $\geq 10^{\mathrm{b}}$ & $61(39)$ & $190(49)$ & 0.044 & $251(46)$ \\
\hline \multicolumn{5}{|l|}{ PSQ-20 sum-score \& subscales ${ }^{a}$} \\
\hline PSQ sum-score & $0.46(0.2)$ & $0.50(0.2)$ & 0.016 & $0.49(0.2)$ \\
\hline Worries & $0.42(0.2)$ & $0.47(0.3)$ & 0.016 & $0.45(0.3)$ \\
\hline Tension & $0.47(0.2)$ & $0.52(0.2)$ & 0.029 & $0.50(0.2)$ \\
\hline Joy & $0.46(0.2)$ & $0.43(0.2)$ & 0.137 & $0.44(0.2)$ \\
\hline Demands & $0.40(0.2)$ & $0.45(0.2)$ & 0.049 & $0.43(0.2)$ \\
\hline \multicolumn{5}{|l|}{ EDI-2 subscales ${ }^{a}$} \\
\hline Drive for thinness & $26.37(6.9)$ & $28.87(6.8)$ & $<0.001$ & $28.16(6.9)$ \\
\hline Impulse regulation & $22.68(6.6)$ & $23.90(7.7)$ & 0.179 & $23.55(7.4)$ \\
\hline Ineffectiveness & $27.03(8.3)$ & $29.73(10.1)$ & 0.006 & $28.96(9.7)$ \\
\hline Social insecurity & $24.35(7.1)$ & $24.59(7.2)$ & 0.849 & $24.52(7.2)$ \\
\hline Body dissatisfaction & $42.76(9.4)$ & $48.58(7.0)$ & $<0.001$ & $46.92(8.16)$ \\
\hline
\end{tabular}

${ }^{\text {a }}$ Data are mean-values (SD).

${ }^{b}$ Data represent frequency values (\%).

${ }^{c} \mathrm{p}$ values refer to the significance of Mann-Whitney-U (continuous data) or Pearson's chi-square tests (categorical data).

Sample Description

A total of $\mathrm{N}=547$ individuals ( $\mathrm{n}=391$ females; $\mathrm{n}=156$ males) with severe obesity (mean BMI of 45,7 $\mathrm{kg} / \mathrm{m}^{2}$ ) from the full spectrum of obesity $\left(\mathrm{BMI}>30 \mathrm{~kg} / \mathrm{m}^{2}\right.$ ) were consecutively recruited for study participation. Out of the total sample, $7 \%$ of the individuals screened positive for panic syndrome according to the Patient Health Questionnaire, and 9\% of the individuals screened positive for other anxiety syndromes. The mean score for depression was 9.7 with a standard deviation of 6.0. For detailed demographic descriptions see table 1. Clinical characteristics of the study sample are displayed in table 2 . We tested both sociodemographic and clinical characteristics for gender differences and discovered that males and females differed significantly, e.g., for age, marital, and employment status. We therefore report characteristics for the total sample and for each gender separately in tables 1 and 2, and we ran the regression analyses for male and female participants separately.

\section{Statistical Analyses}

Sample characteristics in regard to demographic and clinical dimensions are calculated and reported as mean values ( \pm standard deviations (SD)) or frequencies. Correlations of single independent variables with the outcome variable were calculated using nonparametric tests (Spearman's rho) to assess the association between perceived stress and the hypothesized stressors. Furthermore, to assess determination, multiple linear regression analyses were applied to calculate the adjusted $R^{2}$ as a measure of total variation for the hypothesized model. Standardized beta figures are reported as measures for the individual partial variance explanation by single determinants. Model premises for multiple linear regression analyses were tested based on residual statistics and graphical analyses. Regression analyses were run with and without outliers to control for the potential effects of data outliers. Outliers were identified graphically using a boxplot approach, with 'outliers' being defined as any values that are more than 1,5 times the distance of the interquartile range (IQR) higher or lower than the IQR. The PSQ-20 sum score served as the dependent variable, and the five hypothesized constructs (subscales) of the EDI-2 were entered as independent model determinants. 
Table 3. Correlations between the PSQ-20 sum score and relevant EDI-2 subscales

\begin{tabular}{|c|c|c|c|c|c|}
\hline & \multicolumn{5}{|l|}{ EDI-2 subscales } \\
\hline & drive for thinness & impulse regulation & ineffectivity & social insecurity & body dissatisfaction \\
\hline PSQ-20 sum-score & $0.316^{*}$ & $0.590 *$ & $0.702^{*}$ & $0.622^{*}$ & $0.224^{*}$ \\
\hline \multicolumn{6}{|l|}{ EDI-2 subscales } \\
\hline Drive for thinness & - & $0.232^{*}$ & $0.343^{*}$ & $0.226^{*}$ & $0.402^{*}$ \\
\hline Impulse regulation & $0.232^{*}$ & - & $0.667^{*}$ & $0.601^{*}$ & $0.092^{*}$ \\
\hline Ineffectivity & $0.343^{*}$ & $0.667^{*}$ & - & $0.746^{*}$ & $0.234^{*}$ \\
\hline Social insecurity & $0.226^{*}$ & $0.601^{*}$ & $0.746^{*}$ & - & $0.150 *$ \\
\hline Body dissatisfaction & $0.402^{*}$ & $0.092^{*}$ & $0.234^{*}$ & $0.150^{*}$ & - \\
\hline
\end{tabular}

EDI-2 = Eating Disorder Inventory-2. PSQ-20 = Perceived Stress Questionnaire-20.

$* \mathrm{p}<0.05$.

To control for the additional explanation of variance by the hypothesized stressors, the regression analyses were run in three blocks. The symptom load of depression, panic syndrome, and anxiety measured by the PHQ scores were entered in block 1 to assess how much variance of perceived stress is explained by these factors before analyzing the additional variance by the five postulated determinants of perceived stress in block 2. In block 3, BMI scores were added to assess if any additional variance can be explained by the BMI itself. Since significant differences for men and women concerning sociodemographic and clinical characteristics, including the relevant EDI-2 subscales, emerged in the sample characteristics, separate regression models for men and women were applied. Multicollinearity within the regression model was monitored by calculating Tolerance (T) (interpreting values $>0.2$ as acceptable) and the variance inflation factor (VIF) (interpreting values $<5$ as acceptable) accordingly. Autocorrelation among model determinants were tested using the Durbin-Watson test. All statistical analyses were performed using IBM SPSS version 21 (IBM Corporation, Armonk, NY, USA) [44].

\section{Results}

Table 3 shows the Spearman's rho correlations between the PSQ-20 sum scores and the five relevant EDI-2 subscales as well as the Spearman's rho correlations between the five EDI-2 subscales. All of the correlations proved to be significant $(\mathrm{p}<0.05)$, with medium to strong single associations between the PSQ-20 sum score and 'Impulse Regulation', 'Ineffectivity', and 'Social Security' as well as small single associations between the PSQ-20 sum score and 'Drive for Thinness' and 'Body Dissatisfaction'.

The EDI-2 subscales are all significantly correlated, with small-to-medium single associations between all of the five subscales with the exception of 'Body Dissatisfaction' and 'Impulse Regulation' ( $\left.r_{s}=0.092\right)$ and 'Body Dissatisfaction' and 'Social Insecurity' $\left(r_{s}=0.150\right)$, which show significant but weak associations.

The results of the multiple regression analyses for the hypothesized model of 'potentially obesity-related stressors' in individuals with obesity are shown in table 4 . The hypothesized model showed a substantial total variance of perceived stress (adjusted $\mathrm{R}^{2}=0.616$ for men and adjusted $\mathrm{R}^{2}=0.595$ for women) in the investigated sample. Omitting data outliers from the sample before entering the regression analyses did not result in relevant changes to the study results. Hence, no further measures for the correction of outliers were contemplated, and outliers were kept in the data sample.

Neither anxiety nor panic scores proved to be significant determinants in either block of the regression analyses regardless of whether they were performed in the sample women or 
Table 4. Regression analyses for 'potentially obesity-related stressors'a

\begin{tabular}{|c|c|c|c|c|c|c|c|c|c|c|}
\hline & \multicolumn{5}{|c|}{$\operatorname{Men}(n=156)$} & \multicolumn{5}{|c|}{ Women $(n=391)$} \\
\hline & Adj. $R^{2}$ & b (95\% CI) & $\beta$ & $\mathrm{p}$ & Tol. & Adj. $R^{2}$ & $\mathrm{~b}(95 \% \mathrm{CI})$ & $\beta$ & $\mathrm{p}$ & Tol. \\
\hline \multicolumn{11}{|l|}{ Block 1} \\
\hline Constant & $0.413^{*}$ & $0.26(0.22,0.31)$ & & $<0.001$ & & $0.490^{*}$ & $0.28(0.25,0.31)$ & & $<0.001$ & \\
\hline Depression & & $0.02(0.02,0.03)$ & 0.71 & $<0.001$ & 0.757 & & $0.02(0.02,0.02)$ & 0.67 & $<0.001$ & 0.698 \\
\hline Panic & & $-0.02(-0.14,0.11)$ & -0.02 & 0.800 & 0.651 & & $0.03(-0.03,0.08)$ & 0.03 & 0.384 & 0.874 \\
\hline Anxiety & & $-0.14(-0.28,0.00)$ & -0.15 & 0.056 & 0.635 & & $0.03(-0.03,0.08)$ & 0.04 & 0.339 & 0.729 \\
\hline \multicolumn{11}{|l|}{ Block 2} \\
\hline Constant & $0.602^{*}$ & $-0.08(-0.19,0.03)$ & & 0.136 & & $0.587^{*}$ & $-0.06(-0.16,0.04)$ & & 0.267 & \\
\hline Depression & & $0.01(0.01,0.02)$ & 0.34 & $<0.001$ & 0.471 & & $0.01(0.01,0.01)$ & 0.34 & $<0.001$ & 0.365 \\
\hline Panic & & $-0.01(-0.11,0.10)$ & -0.01 & 0.923 & 0.645 & & $0.00(-0.05,0.05)$ & 0.00 & 0.977 & 0.825 \\
\hline Anxiety & & $-0.08(-0.20,0.04)$ & -0.09 & 0.188 & 0.596 & & $0.04(-0.01,0.09)$ & 0.07 & 0.086 & 0.700 \\
\hline \multicolumn{11}{|l|}{ EDI-2 subscales } \\
\hline Drive for thinness & & $0.01(0.00,0.01)$ & 0.21 & $<0.001$ & 0.753 & & $0.00(0.00,0.00)$ & 0.01 & 0.805 & 0.756 \\
\hline Ineffectiveness & & $0.01(0.00,0.01)$ & 0.28 & 0.003 & 0.313 & & $0.00(0.00,0.01)$ & 0.18 & 0.003 & 0.287 \\
\hline Impulse regulation & & $0.00(0.00,0.00)$ & 0.01 & 0.861 & 0.536 & & $0.00(0.00,0.01)$ & 0.12 & 0.015 & 0.445 \\
\hline Social insecurity & & $0.01(0.00,0.01)$ & 0.22 & 0.005 & 0.414 & & $0.01(0.00,0.01)$ & 0.17 & 0.001 & 0.394 \\
\hline Body dissatisfaction & & $0.00(0.00,0.00)$ & -0.01 & 0.904 & 0.797 & & $0.00(0.00,0.01)$ & 0.11 & 0.003 & 0.828 \\
\hline \multicolumn{11}{|l|}{ Block 3} \\
\hline Constant & $0.616^{*}$ & $0.01(-0.11,0.14)$ & & 0.874 & & $0.595^{*}$ & $0.04(-0.08,0.15)$ & & 0.512 & \\
\hline Depression & & $0.01(0.01,0.02)$ & 0.35 & $<0.001$ & 0.469 & & $0.01(0.01,0.01)$ & 0.33 & $<0.001$ & 0.364 \\
\hline Panic & & $-0.01(-0.11,0.09)$ & -0.02 & 0.809 & 0.643 & & $0.01(-0.05,0.06)$ & 0.01 & 0.806 & 0.821 \\
\hline Anxiety & & $-0.08(-0.20,0.04)$ & -0.09 & 0.190 & 0.595 & & $0.04(-0.01,0.09)$ & 0.06 & 0.102 & 0.699 \\
\hline \multicolumn{11}{|l|}{ EDI-2 subscales } \\
\hline Drive for thinness & & $0.01(0.00,0.01)$ & 0.22 & $<0.001$ & 0.751 & & $0.00(0.00,0.00)$ & 0.01 & 0.897 & 0.755 \\
\hline Ineffectiveness & & $0.01(0.00,0.01)$ & 0.24 & 0.010 & 0.304 & & $0.00(0.00,0.01)$ & 0.20 & 0.001 & 0.284 \\
\hline Impulse regulation & & $0.00(0.00,0.00)$ & 0.00 & 0.998 & 0.533 & & $0.00(0.00,0.01)$ & 0.11 & 0.023 & 0.444 \\
\hline Social insecurity & & $0.01(0.00,0.01)$ & 0.26 & 0.001 & 0.403 & & $0.01(0.00,0.01)$ & 0.18 & 0.001 & 0.394 \\
\hline Body dissatisfaction & & $0.00(0.00,0.00)$ & 0.05 & 0.430 & 0.694 & & $0.00(0.00,0.01)$ & 0.12 & 0.001 & 0.823 \\
\hline BMI & & $0.00(-0.01,0.00)$ & -0.14 & 0.013 & 0.811 & & $0.00(0.00,0.00)$ & -0.10 & 0.002 & 0.965 \\
\hline
\end{tabular}

Adj. $\mathrm{R}^{2}=$ Adjusted $\mathrm{R}^{2} ; \beta=$ standardized beta; Tol. = Tolerance.

${ }^{a}$ Outcome: perceived stress, assessed with the PSQ-20 sum-score.

$* \mathrm{p}<0.05$.

men. Depression scores, however, were found to be significant determinants for perceived stress in both men and women with obesity and explained a substantial part of variance when entered in block 1 (adjusted $\mathrm{R}^{2}=0.413$ for men and adjusted $\mathrm{R}^{2}=0.587$ for women). However, as shown in block 2 of our regression analyses, the five postulated stressors (EDI-2 subscales) showed an additional substantial part of explained variance when added to the regression model. The total variance explanation increased by almost $20 \%$ for men and $10 \%$ for women. Including BMI as a further determinant in block 3 led to a further increase of the explained variance of $1.4 \%$ for men and $0.8 \%$ for women.

Among the included determinants, the construct 'Social Insecurity' showed the highest single variance (standardized beta $=0.26 ; \mathrm{p}=0.001$ ) for men, followed by 'Ineffectiveness' (standardized beta $=0.24 ; \mathrm{p}=0.010$ ) and 'Drive for Thinness' (standardized beta $=0.22 ; \mathrm{p}<$ 0.001), whereas 'Impulse Regulation' and 'Body Dissatisfaction' did not significantly determine perceived stress in men with obesity. In women, four of the five included potential stressors (EDI-2 subscales) proved to be significant determinants of perceived stress with 'Ineffec- 
tiveness' showing the highest single variance (standardized beta $=0.20 ; p=0.001$ ), followed by 'Social Insecurity' (standardized beta $=0.18$; $p=0.001$ ), 'Body Dissatisfaction' (standardized beta $=0.12 ; \mathrm{p}=0.001$ ) and 'Impulse Regulation' (standardized beta $=0.11 ; \mathrm{p}=$ 0.023). 'Drive for Thinness' did not determine significantly perceived stress in women with obesity.

\section{Discussion}

To the best of our knowledge, this is the first study to investigate the relationship of the here hypothesized potentially obesity-related factors with perceived stress in individuals with obesity. The results predominantly imply that the answer to study question 1 ('Do the hypothesized potentially obesity-related stressors show relationships with perceived stress?') is yes. In regard to study question 2 ('To what extent do the hypothesized stressors (additionally) determine perceived stress in individuals with obesity?'), it was found that the magnitude of determination varies among the different stressors and between the two gender subgroups of the investigated sample.

Although not all of the hypothesized determinants showed significant influence on perceived stress for males and females with obesity, higher scores on the respective subscales representing potential stressors were consistently associated with higher levels of perceived stress.

Overall, the results show strong effects of the hypothesized factors on perceived stress in the investigated population of obesity-affected individuals. The findings may contribute to the understanding of the chronic nature of obesity, given that perceived stress may play a role in obesogenic eating behavior [8] via activation of the HPA axis system and increased cortisol levels [20-22].

Specifically targeting the identified stressors within treatment regimens may be seen as a promising component to tackle the interplay of obesity, stress, and eating. However, the findings of this cross-sectional study do not infer a causal relationship of the investigated determinants and perceived stress in individuals with obesity. Further investigation within longitudinal (interventional) designs is needed to further investigate the interactions of potentially obesity-related stressors and perceived stress in affected individuals.

According to the study's results, the investigated dimensions of 'Body Dissatisfaction', 'Drive for Thinness', 'Impulse Regulation', 'Ineffectiveness' and 'Social Insecurity' may be cautiously interpreted to play different roles for men and women with obesity. 'Ineffectiveness' and 'Social Insecurity' turned out to substantially determine perceived stress in both gender subgroups. In women, 'Impulse Regulation' and 'Body Dissatisfaction' seem to play important roles in the determination of perceived stress, whereas 'Drive for Thinness' does not determine perceived stress significantly in the investigated sample of women with obesity. In men, 'Drive for Thinness' determines perceived stress significantly, whereas 'Impulse Regulation' and 'Body Dissatisfaction' do not in the context of this study.

The construct of 'Ineffectiveness' was one of the most influential determinants within the hypothesized model for both men and women, and it can be seen as a concept addressing several obesity-related issues. Firstly, it may be related to the (often frustrating) experience of affected individuals in weight reduction programs and dieting in general. The often small and unsustainable effects of (noninvasive) weight reduction programs may thereby contribute to the self-perception of being 'ineffective as a person' [45]. Secondly, the perceived ineffectiveness in specifically controlling eating behavior (e.g., to eat healthier) or self-efficacy perception related to other plans of behavior change (e.g., exercise routines) may be present in affected individuals. Thirdly, the social consequences of obesity in terms of stigma and 
discrimination may reinforce the perception of ineffectiveness if, for example, repeated attempts at societal participation (e.g., job applications) are unsuccessful [46].

'Impulsivity' was the second most important driver of perceived stress in females, and it may relate to perceived deficits in regulating and willingly responding to obesogenic impulses. Relevant issues can be seen in the impulse to eat in general, to eat or drink calorie-dense/ palatable aliments or drinks (including alcohol), or to eat outside of a reasonable time structure (e.g., night eating) [47]. Being unable to control one's own behavior on recurrent and (highly) frequent occasions during day-to-day routines may well constitute an uncontrollable ego-type stress in the sense that such uncontrollable (impulsive) behavior may lead to adverse effects for the individual, not only in terms of weight gain but also in regard to other important areas of life such as social relationships or work [6, 30, 31].

The dimension of 'Social Insecurity' was found to be important in both males and females. The construct may be seen as more directly representing the relevance of assumed or experienced stigma or discrimination. Furthermore, 'Social Insecurity' may reflect issues of unsatisfactory self-perceptions or assumed negative appraisal by others, related to, e.g., body image, physical attractiveness, and expected social acceptance (see also [48]).

'Drive for Thinness' itself was the factor with the potentially most explicit and direct relation to obesity within the hypothesized model, and it only showed a relevant variance explanation in the regression analysis within the subgroup of males.

In contrast, 'Body Dissatisfaction' only showed a relevant variance explanation in females. These findings may be very cautiously interpreted as being indicative of gender-specific differences in the way in which different specific stressors are perceived in individuals with obesity. However, direct comparison between the two sexes was not conducted in the present study due to demographic differences (in regard to age, marital and employment status, see table 1) between the two gender subgroups. The latter differences may indeed constitute relevant biases in regard to the detected gender differences on relevant stressors. It therefore remains the domain of future studies to further analyze the differential importance of the hypothesized stressors in women and men.

However, the overall findings of this cross-sectional study, which indeed cannot infer causality, may nevertheless indicate innovative and promising new scientific and clinical targets within conservative weight management programs and cognitive-behavioral approaches to obesity therapy $[47,52]$. Based on the findings of this study, it can be cautiously recommended to include the hypothesized dimensions in diagnostic regimes to identify patients with high scores for the dimensions of 'Drive for Thinness', 'Ineffectiveness', 'Impulsivity', 'Social Insecurity', or 'Body Dissatisfaction' (e.g. by the EDI-2) [39-41] in individuals with obesity. The latter dimensions may specifically be addressed by educational material, group-therapy sessions or one-on-one counseling to ultimately reduce perceived stress and associated negative effects on the quality of life and stress-associated disorders in individuals with obesity [52].

The dimension of 'Drive for Thinness' could be addressed by using interventions with an emphasis on a healthy lifestyle instead of focusing on explicit weight reduction. Bacon and colleagues [50] found a significant reduction on the 'Drive for Thinness' scale in their 'Health at Every Size' intervention group that primarily focused on an overall healthy lifestyle [50].

To address 'Ineffectiveness', interventions focusing on self-efficacy should be considered. In this context a recent meta-analysis showed that interventions focusing on 'action planning', 'time management', 'prompt self-monitoring of behavioral outcome' and 'plan social support/ social change' significantly improved self-efficacy in obese participants [51].

A therapeutic strategy to address 'impulsivity' may be represented by an innovative group-based intervention program developed by our own group (Schag and colleagues) that specifically focuses on impulsivity [52] (ongoing study). Mindfulness-based therapeutic 
approaches [53] and elements of Acceptance and Commitment Therapy (ACT) [54] may be promising strategies to tackle body dissatisfaction in women with eating disorders [54]. Furthermore, evidence can be found for the differential efficacy of cognitive restructuring versus an intervention based on a gratitude diary [56] to address body dissatisfaction. Notably, the gratitude group was twice as likely to complete the intervention compared to the cognitive restructuring group and the control group [56]. 'Social Insecurity' may be addressed by interventions such as social skills training [55] which has been shown to be effective, e.g., for social anxiety [55].

From a more general point of view, it has to be noted that indeed all of the determinants of perceived stress investigated here may well be active in a non-obese population too. However, the primary aim of this study was to test the assumption of whether theoretically derived (potentially obesogenic) factors are relevant determinants of perceived stress in a population of individuals with obesity. The comparison to individuals with normal weight awaits future research and clinical targeting in this specific population.

\section{Limitations}

Despite clear and strong associations between single determinants and the outcome variable and the strong overall impact of the hypothesized models on perceived stress, this study does not infer causal relationships of the investigated dimensions due to its crosssectional design.

In regard to the question of a causal relationship of dimensions such as ineffectiveness with perceived stress, experimental research paradigms (for example, by inducing perceptions of ineffectiveness) may aid in clarifying whether or not a specific role of such dimensions exists in the genesis of perceived stress in individuals with obesity. Furthermore, the question of whether relative differences are detectable in normal-weight/underweight individuals when compared to individuals with obesity might be addressed. Prospective clinical studies that specifically address and seek to alter perceptions of ineffectiveness or impulsivity might be a further way to investigate the role of such potential stressors in the course of obesity in affected individuals [52].

This study only included individuals who are seeking clinical examination and treatment for obesity. The results therefore cannot easily be transferred to the general population of individuals with obesity. A selection bias towards individuals with higher levels of frustration, psychological strain, or higher motivation for treatment may well be present. However, stress levels as well as prevalence rates for anxiety and depression in the study sample resemble the rates of other large (representative) studies on individuals with obesity [37, 57].

\section{Conclusion}

This study shows a substantial determination of perceived stress by potentially obesityrelated cognitive and emotional stressors in females and males with obesity. The findings of this study may contribute to the improved understanding of potentially specific stressors in obese individuals. Furthermore, the findings of this study may be cautiously interpreted as being indicative of gender-specific perspectives in regard to the differential relevance of determinants of stress in individuals with obesity. The results of this study may implicate novel diagnostic and therapeutic approaches in the context of, e.g., cognitive-behavioral (group) therapy for individuals with obesity. Future research on the causes and determinants of perceived stress in individuals with obesity using longitudinal (interventional) designs may be seen as promising in regard to the improved understanding of specific stressors in individuals with obesity and their role in the onset, course and treatment of obesity. 


\section{Acknowledgments}

The authors thank all contributing staff at the Department of Psychosomatic Medicine and Psychotherapy for their dedicated work on the conduct of this study. The authors especially thank Ms. Sabrina Ölschlaeger for her most professional assistance during the study's administration. KEG receives a grant by the Ministry of Science Baden-Wuerttemberg and the European Social Fund and is partially supported by the Athene program, a project of the Excellence Initiative of the German federal and state governments.

\section{Disclosure Statement}

All authors declare to have no conflict of interest in regard to the conduct and content of this study and manuscript.

\section{References}

1 Barrington WE, Beresford SA, McGregor BA, White E: Perceived stress and eating behaviors by sex, obesity status, and stress vulnerability: findings from the vitamins and lifestyle (vital) study. J Acad Nutr Diet 2014; 114:1791-1799.

-2 Sominsky L, Spencer SJ: Eating behavior and stress: a pathway to obesity. Front Psychol 2014;5:434.

-3 Patterson ZR, Abizaid A: Stress induced obesity: lessons from rodent models of stress. Front Neurosci 2013; 7:130.

-4 Barrington WE, Ceballos RM, Bishop SK, McGregor BA, Beresford SA: Perceived stress, behavior, and body mass index among adults participating in a worksite obesity prevention program, Seattle, 2005-2007. Prev Chronic Dis 2012;9:E152.

5 Groesz LM, McCoy S, Carl J, Saslow L, Stewart J, Adler N, Laraia B, Epel E: What is eating you? Stress and the drive to eat. Appetite 2012;58:717-721.

6 Moore CJ, Cunningham SA: Social position, psychological stress, and obesity: a systematic review. J Acad Nutr Diet 2012;112:518-526.

7 Adam TC, Epel ES: Stress, eating and the reward system. Physiol Behav 2007;91:449-458.

-8 Torres SJ, Nowson CA: Relationship between stress, eating behavior, and obesity. Nutrition 2007;23:887-894.

-9 Pecoraro N, Reyes F, Gomez F, Bhargava A, Dallman MF: Chronic stress promotes palatable feeding, which reduces signs of stress: feedforward and feedback effects of chronic stress. Endocrinology 2004;145:3754-3762.

10 Tataranni PA, Larson DE, Snitker S, Young JB, Flatt JP, Ravussin E: Effects of glucocorticoids on energy metabolism and food intake in humans. Am J Physiol 1996;271:E317-325.

11 Greeno CG, Wing RR: Stress-induced eating. Psychol Bull 1994;115:444-464.

12 Scott KA, Melhorn SJ, Sakai RR: Effects of chronic social stress on obesity. Curr Obes Rep 2012;1:16-25.

13 Goldstein DS, Kopin IJ: Evolution of concepts of stress. Stress 2007;10:109-120.

14 Lee CY, Abizaid A: The gut-brain-axis as a target to treat stress-induced obesity. Front Endocrinol (Lausanne) 2014;5:117.

15 Morris MJ, Beilharz JE, Maniam J, Reichelt AC, Westbrook RF: Why is obesity such a problem in the 21st century? The intersection of palatable food, cues and reward pathways, stress, and cognition. Neurosci Biobehav Rev 2015;58:36-.45.

16 Bose M, Olivan B, Laferrere B: Stress and obesity: The role of the hypothalamic-pituitary-adrenal axis in metabolic disease. Curr Opin Endocrinol Diabetes Obes 2009;16:340-346.

$\checkmark 17$ Gluck ME, Geliebter A, Hung J, Yahav E: Cortisol, hunger, and desire to binge eat following a cold stress test in obese women with binge eating disorder. Psychosom Med 2004;66:876-881.

-18 Tsigos C, Chrousos GP: Hypothalamic-pituitary-adrenal axis, neuroendocrine factors and stress. J Psychosom Res 2002;53:865-871.

19 Zellner DA, Loaiza S, Gonzalez Z, Pita J, Morales J, Pecora D, Wolf A: Food selection changes under stress. Physiol Behav 2006;87:789-793.

20 George SA, Khan S, Briggs H, Abelson JL: Crh-stimulated cortisol release and food intake in healthy, non-obese adults. Psychoneuroendocrinology 2010;35:607-612.

-21 Newman E, O'Connor DB, Conner M: Daily hassles and eating behaviour: the role of cortisol reactivity status. Psychoneuroendocrinology 2007;32:125-132.

-22 Epel E, Lapidus R, McEwen B, Brownell K: Stress may add bite to appetite in women: a laboratory study of stress-induced cortisol and eating behavior. Psychoneuroendocrinology 2001;26:37-49.

23 Foss B, Dyrstad SM: Stress in obesity: cause or consequence? Med Hypotheses 2011;77:7-10.

24 O'Connor DB, Jones F, Conner M, McMillan B, Ferguson E: Effects of daily hassles and eating style on eating behavior. Health Psychol 2008;27(1 suppl):S20-31.

-25 Buwalda B, Blom WA, Koolhaas JM, van Dijk G: Behavioral and physiological responses to stress are affected by high-fat feeding in male rats. Physiol Behav 2001;73:371-377. 
Junne et al.: Determinants of Perceived Stress in Individuals with Obesity: Exploring the Relationship of Potentially Obesity-Related Factors and Perceived Stress

$-26$

$>27$

827-835.

28 Volkow ND, Wise RA: How can drug addiction help us understand obesity? Nat Neurosci 2005;8:555-560.

29 Dallman MF, Akana SF, Laugero KD, Gomez F, Manalo S, Bell ME, Bhatnagar S: A spoonful of sugar: feedback signals of energy stores and corticosterone regulate responses to chronic stress. Physiol Behav 2003;79:3-12.

-30 Wallis DJ, Hetherington MM: Stress and eating: the effects of ego-threat and cognitive demand on food intake in restrained and emotional eaters. Appetite 2004;43:39-46.

-31 Heatherton TF, Herman CP, Polivy J: Effects of physical threat and ego threat on eating behavior. J Pers Soc Psychol 1991;60:138-143.

-32 Tamashiro KL, Nguyen MM, Fujikawa T, Xu T, Yun Ma L, Woods SC, Sakai RR: Metabolic and endocrine consequences of social stress in a visible burrow system. Physiol Behav 2004;80:683-693.

-33 Tamashiro KL, Nguyen MM, Sakai RR: Social stress: from rodents to primates. Front Neuroendocrinol 2005; 26:27-40

-34 Pijlman FT, Wolterink G, Van Ree JM: Physical and emotional stress have differential effects on preference for saccharine and open field behaviour in rats. Behav Brain Res 2003;139:131-138.

-35 Tamashiro KL, Hegeman MA, Sakai RR: Chronic social stress in a changing dietary environment. Physiol Behav 2006;89:536-542.

-36 Bjorntorp P: Do stress reactions cause abdominal obesity and comorbidities? Obesity Rev 2001;2:73-86.

- 37 Fliege H, Rose M, Arck P, Walter OB, Kocalevent RD, Weber C, Klapp BF: The Perceived Stress Questionnaire (PSQ) reconsidered: validation and reference values from different clinical and healthy adult samples. Psychosom Med 2005;67:78-88.

38 Levenstein S, Prantera C, Varvo V, Scribano ML, Berto E, Luzi C, Andreoli A: Development of the perceived stress questionnaire: a new tool for psychosomatic research. J Psychosom Res 1993;37:19-32.

39 Paul T, Thiel A: Eating Disorder Inventory-2 (EDI-2): Deutsche Version. Göttingen, Hogrefe, 2005

40 Packianathan IC, Sheikh M, Feben S, Finer N: The eating disorder inventory in a UK National Health Service obesity clinic and its response to modest weight loss. Eat Behav 2002;3:275-284.

-41 Garner DM: Eating Disorder Inventory-2. Odessa, Psychological Assessment, Resources 1991.

-42 Spitzer RL, Kroenke K, Williams JB: Validation and utility of a self-report version of PRIME-MD: The PHQ primary care study. Primary care evaluation of mental disorders. Patient health questionnaire. JAMA 1999; 282:1737-1744.

43 Gräfe K, Zipfel S, Herzog W, Löwe B: Screening psychischer Störungen mit dem 'Gesundheitsfragebogen für Patienten (PHQ-D)'. Diagnostica 2004;50:171-181.

44 IBM Corp: IBM SPSS statistics for Windows, version 21.0, IBM Corp, Armonk, New York, 2012.

-45 Wu T, Gao X, Chen M, Van Dam R: Long-term effectiveness of diet-plus-exercise interventions vs. diet-only interventions for weight loss: a meta-analysis. Obes Rev 2009;10:313-323.

46 Giel KE, Zipfel S, Alizadeh M, Schaffeler N, Zahn C, Wessel D, Hesse FW, Thiel S, Thiel A: Stigmatization of obese individuals by human resource professionals: an experimental study. BMC Public Health 2012;12:525.

47 Schag K, Schonleber J, Teufel M, Zipfel S, Giel KE: Food-related impulsivity in obesity and binge eating disorder - a systematic review. Obes Rev 2013;14:477-495.

48 Dickerson SS, Gruenewald TL, Kemeny ME: When the social self is threatened: shame, physiology, and health. J Pers 2004;72:1191-1216.

49 Goeders NE: The impact of stress on addiction. Eur Neuropsychopharmacol 2003;13:435-441.

50 Bacon L, Stern JS, Van Loan MD, Keim NL: Size acceptance and intuitive eating improve health for obese, female chronic dieters. J Am Diet Assoc 2005;105:929-936.

51 Olander EK, Fletcher H, Williams S, Atkinson L, Turner A, French DP: What are the most effective techniques in changing obese individuals' physical activity self-efficacy and behaviour: a systematic review and metaanalysis. Int J Behav Nutr Phys Activity 2013;10:1.

-52 Schag K, Leehr EJ, Martus P, Bethge W, Becker S, Zipfel S, Giel KE: Impulsivity focused group intervention to reduce binge eating episodes in patients with binge eating disorder: study protocol of the randomised controlled IMPULS trial. BMJ Open 2015;5:e009445.

53 Alberts H, Thewissen R, Raes L: Dealing with problematic eating behaviour. The effects of a mindfulness-based intervention on eating behaviour, food cravings, dichotomous thinking and body image concern. Appetite 2012;58:847-851.

54 Pearson AN, Follette VM, Hayes SC: A pilot study of acceptance and commitment therapy as a workshop intervention for body dissatisfaction and disordered eating attitudes. Cogni Behav Pract 2012;19:181-197.

55 Bögels SM, Voncken M: Social skills training versus cognitive therapy for social anxiety disorder characterized by fear of blushing, trembling, or sweating. Int J Cogn Ther 2008;1:138-150.

-56 Geraghty AW, Wood AM, Hyland ME: Attrition from self-directed interventions: Investigating the relationship between psychological predictors, intervention content and dropout from a body dissatisfaction intervention. So Sci Med 2010;71:30-37.

57 Rief W, Nanke A, Klaiberg A, Braehler E: Base rates for panic and depression according to the brief patient health questionnaire: a population-based study. J Affect Disord 2004;82:271-276. 